\title{
STUDIES OF THE URICOGENIC EFFECT OF 2-SUBSTITUTED THIADIAZOLES IN MAN *
}

\author{
By IRWIN H. KRAKOFF AND M. EARL BALIS \\ (From the Divisions of Clinical Chemotherapy and Nucleoprotein Chemistry, Sloan-Kettering \\ Institute for Cancer Research; Department of Medicine, Memorial and James \\ Ezing Hospitals; and Department of Medicine, Cornell University \\ Medical College, New York, N. Y.)
}

(Submitted for publication November 12, 1958; accepted February 2, 1959)

Several substances have been found to affect the serum levels of uric acid by influencing the renal mechanisms of uric acid excretion. Among these are agents which inhibit tubular reabsorption of uric acid, e.g., salicylates (1) and probenicid (2), and those which appear to enhance reabsorption, e.g., pyrazinamide (3) and azathymine (4). Other chemical and physical agents are known to produce extensive tissue destruction with resulting elevation of serum and urine uric acid, presumably due in large part to the oxidation of purines coming from the degradation of nucleic acids and soluble nucleotides. This mechanism is most often seen in the leukemias and lymphomas in which $\mathrm{X}$-rays, the nitrogen mustards and adrenocortical steroids can destroy leukocytes and lymphoid tissue with resulting hyperuricemia and uricosuria (5).

In 1956 it was reported (6) that 2-ethylamino1,3,4 thiadiazole appeared to have the unique property of causing an increase in uric acid production not related to tissue destruction. The purpose of this paper is to describe further experiences with this drug and related compounds. The anti-tumor effects of these agents in animals have been described previously (6-9). Three compounds in this series have been studied in humans: 2-amino-1,3,4 thiadiazole; 2 -ethylamino-1,3,4 thiadiazole; and 2,5 diamino-1,3,4 thiadiazole (Figure 1).

\section{MATERIALS AND METHODS}

Thirty-three studies were performed in 18 patients with far-advanced, nonresectable cancer (a single patient

* This work was supported by Research Grants CY3215, C1889 and CY3190 from the National Cancer Institute, Public Health Service; by a grant from the American Cancer Society and the Damon Runyon Memorial Fund for Cancer Research; and institutional grants from the Lasker Foundation, and the Grant Foundation. had hypertensive cardiovascular disease and no known neoplastic disease). All patients were hospitalized during the studies. They received a hospital diet low in purines and an attempt was made to keep the caloric intake constant, although this could not always be rigidly maintained in patients with far-advanced cancer. There were, however, no wide daily fluctuations in dietary intake. Daily 24 hour urine collections were made using thymol as a preservative. If the specimens were not analyzed immediately after collection, aliquots were frozen for storage until analyzed.

Urine uric acid analyses were performed by a colorimetric method employing the enzyme uricase. This method has been described in detail elsewhere (5). It is a modification of the method of Archibald (10) in which color is developed with phosphotungstic acid and sodium polyanethol sulfonate. Duplicate specimens of each sample are analyzed and one specimen of each pair is incubated with uricase ${ }^{1}$ prior to color development. The difference between the uricase-treated and the untreated specimens was considered to represent true uric acid. Blood uric acid was measured by the same technique; however, only occasional samples were subjected to incubation with uricase.

This method has been found accurate and highly specific. In order to verify further the authenticity of the material which was measured colorimetrically as uric acid in these studies, specimens of urine from a patient before, during and after treatment with 2-ethylamino thiadiazole were analyzed for uric acid by ultra-
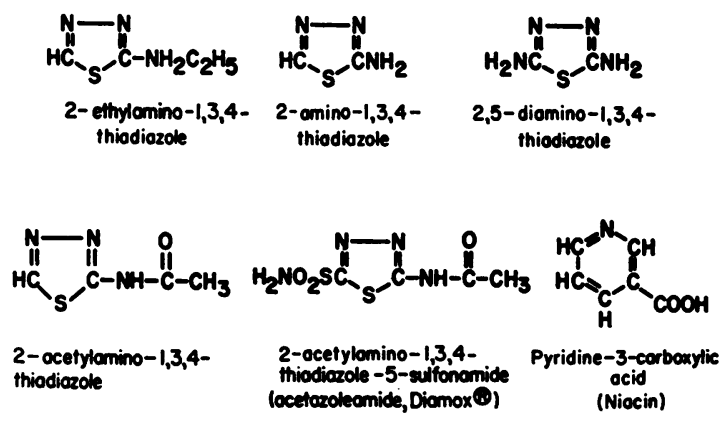

Fig. 1. Structural Formulae of the Thiadiazoles, Niacin and Some Related Compounds

${ }^{1}$ Stero Kems Co., Flushing, N. Y. 
violet spectrophotometry (11). The values obtained by this technique correlated closely with those obtained colorimetrically.

Determinations of total nitrogen were made by acid digestion and direct Nesslerization (12).

For determination of isotope content, uric acid was isolated from the urine by precipitating at $\mathrm{pH} 2$. The crude uric acid was redissolved in alkali, decolorized with charcoal and reprecipitated three times. The purity was checked by examination of the ultraviolet absorption spectrum. $\mathrm{C}^{14}$ content was determined by assaying known amounts as thin films on aluminum planchets with a Geiger-Muller internal flow counter using helium-isobutane gas. Activity was sufficient to give an accuracy of 10 per cent or better (13). Specimens were prepared for $\mathrm{N}^{15}$ analysis as described by Rittenberg (14) by Kjeldahl digestion and treatment of the ammonia with sodium hypobromite. The isotopic ratio was determined with a Consolidated-Nier Model No. 21-201 ratio mass spectrometer.

The thiadiazole compounds ${ }^{2}$ are white, water-soluble powders. The formulae are shown in Figure 1. They were administered to patients in single daily doses orally in capsules. The dosage of 2-ethylaminothiadiazole was

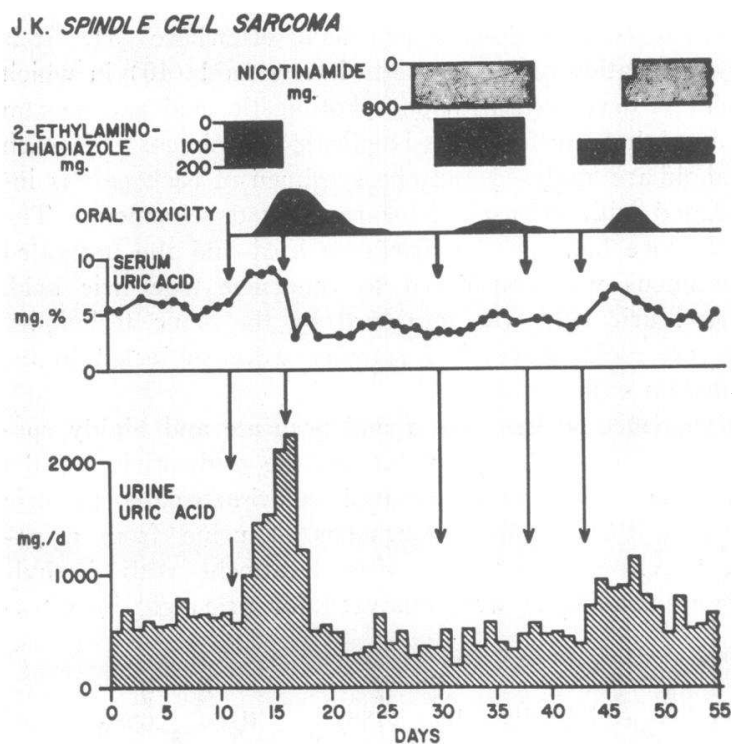

Fig. 2. Course of a Patient Treated with 2-EthylAmino-1,3,4 Thiadiazole

Note the prompt rise in serum and urine uric acid produced by the thiadiazole alone, the absence of the effect when nicotinamide was given concurrently and the reversal of the effect when nicotinamide was started after the thiadiazole effect had developed.

2 2-Amino-1,3,4 thiadiazole and 2-ethylamino-1,3,4 thiadiazole were supplied by Eastman Kodak Co., Rochester, N. Y., and Lederle Laboratories Division of American Cyanamid Co., Pearl River, N. Y. 2,5-Diamino-1,3,4 thiadiazole was purchased from Aldrich Chemical Co., Milwaukee, Wisc.
25 to $200 \mathrm{mg}$. daily. 2-Amino-thiadiazole was used only at a dose of $50 \mathrm{mg}$. daily and 2,5-diamino-thiadiazole was given in doses of up to $2 \mathrm{Gm}$. daily.

Nicotinamide was given orally in divided doses every 6 or 12 hours.

$o$-Diazo-acetyl-L-serine (azaserine) ${ }^{3}$ (15) and 6-diazo5-oxo-L-norleucine $(\mathrm{DON})^{3}(16)$ were given orally in capsules either every eight hours or once daily.

Sodium formate- $\mathrm{C}^{14}$, with an activity of $1 \mathrm{mc}$. per $\mathrm{mM}$, and adenine- $8-\mathrm{C}^{14}$, with an activity of $8.9 \mathrm{mc}$. per $\mathrm{mM}$, were given intravenously over a period of 45 minutes. Ammonium chloride- $\mathrm{N}^{15}, 30$ atom per cent excess, was given intravenously in a dose of $0.5 \mathrm{Gm}$. on each occasion over a period of two hours.

\section{RESULTS}

\section{2-Ethylamino-1,3,4 thiadiazole (hereafter} called EA-TDA), the first of these compounds to be employed, has been studied in 17 patients.

The results of these studies are shown in Table I. No evidence of tumor regression was seen in any of the patients studied. In each patient, glossitis occurred within four to six days of treatment at a dose of $200 \mathrm{mg}$. daily. This appeared initially as a diffuse erythema of the tongue, followed by small marginal ulcerations. In the more severe cases, there was ulceration of the gingival surfaces of the lips and erythema of face, perianal region and scrotum or vagina. If smaller doses were used, the onset of glossitis was delayed but occurred when a similar total dose had been given. Regardless of the dose or severity of the reaction, the toxicity subsided within two to five days after administration of EA-TDA was discontinued. In each patient to whom this compound was administered, there was a marked rise in serum uric acid with a parallel rise in urine uric acid. When the administration of the compound was stopped, there was a prompt return to normal in both serum and urine uric acid. The increase in uric acid levels occurred without elevation of the blood urea nitrogen which was measured three to seven times weekly. The urine volumes were adequate and fairly constant during control and treatment periods. Urine total nitrogen was measured in five patients. No significant changes were seen during treatment with EA-TDA, indicating that the uricosuria was not merely representative of a general negative nitrogen balance. An example of the response to this compound is seen in Figure

\footnotetext{
${ }^{3}$ Supplied by Parke, Davis and Company, Detroit, Mich.
} 
TABLE I

Effect of 2-ethylamino-1,3,4 thiadiazole on uric acid production

\begin{tabular}{|c|c|c|c|c|c|c|c|c|c|c|c|}
\hline \multirow[b]{2}{*}{$\begin{array}{l}\text { Patient, } \\
\text { age, } \\
\text { diagnosis }\end{array}$} & \multicolumn{2}{|c|}{ Control period } & \multicolumn{4}{|c|}{ EA-TDA period } & \multicolumn{5}{|c|}{ EA-TDA and nicotinamide } \\
\hline & $\begin{array}{l}\text { Serum } \\
\text { U.A. } \\
\text { (max.) }\end{array}$ & $\begin{array}{c}\text { Urine } \\
\text { U.A. } \\
\text { (mean) }\end{array}$ & Dose & $\begin{array}{l}\text { Days } \\
\text { of } \\
\text { treat- } \\
\text { ment }\end{array}$ & $\begin{array}{c}\text { Serum } \\
\text { U.A. } \\
\text { (max.) }\end{array}$ & $\begin{array}{c}\text { Urine } \\
\text { U.A. } \\
\text { (mean*) }\end{array}$ & Dose & $\begin{array}{l}\text { Nicotin- } \\
\text { amide }\end{array}$ & $\begin{array}{c}\text { Days } \\
\text { of } \\
\text { treat- } \\
\text { ment }\end{array}$ & $\begin{array}{l}\text { Serum } \\
\text { U.A. } \\
\text { (max.) }\end{array}$ & $\begin{array}{l}\text { Urine } \\
\text { U.A. } \\
\text { (mean) }\end{array}$ \\
\hline 1. J. A., 62 & $\begin{array}{l}m g . \% \\
6.1\end{array}$ & $\begin{array}{l}m g . / d a y \\
296\end{array}$ & $\begin{array}{c}m g . / d a y \\
200\end{array}$ & 5 & $\begin{array}{l}m g . \% \\
24.6\end{array}$ & $\begin{array}{l}m g . / d a y \\
982\end{array}$ & $m g . / d a y$ & mg./day & & $m g . \%$ & $m g . / d a y$ \\
\hline $\begin{array}{l}\text { Carcinoma tongue } \\
2 . \text { S. K., } 20 \\
\text { Carcinoma salivary } \\
\text { gland }\end{array}$ & 4.0 & 335 & 200 & 3 & 13.8 & 759 & & & & & \\
\hline $\begin{array}{l}\text { 3. F. G., } 40 \\
\text { Carcinoma breast }\end{array}$ & 4.6 & 353 & 200 & 4 & 15.0 & 1,167 & 200 & 200 & 3 & 12.9 & 1,134 \\
\hline $\begin{array}{l}\text { 4. G. R., } 64 \\
\text { Carcinoma kidney }\end{array}$ & 7.4 & 563 & 200 & 4 & 13.2 & 1,769 & & & & & \\
\hline $\begin{array}{l}\text { 5. H. M., } 39 \\
\text { Carcinoma cervix }\end{array}$ & 6.7 & 227 & 200 & 5 & 11.2 & 536 & 200 & 600 & 4 & 6.4 & 489 \\
\hline $\begin{array}{l}\text { 6. J K , 34 } \\
\text { Fibrosarcoma }\end{array}$ & 61 & 651 & 200 & 5 & 8.9 & 1,591 & 200 & 800 & 8 & 4.8 & 436 \\
\hline $\begin{array}{l}\text { 7. J. G , } 57 \\
\text { Carcinoma rectum }\end{array}$ & 3.0 & 608 & 200 & 4 & 15.0 & 1,920 & & & & & \\
\hline $\begin{array}{l}\text { 8. B. C., } 56 \\
\text { Hypertensive } \\
\text { cardiovascular } \\
\text { disease }\end{array}$ & 5.5 & 667 & 100 & 3 & 15.6 & 1,599 & & & & & \\
\hline $\begin{array}{l}\text { 6. J. K., } 34 \\
\text { Fibrosarcoma }\end{array}$ & 4.4 & 451 & 100 & 5 & 7.2 & 920 & 100 & $\begin{array}{l}50- \\
800\end{array}$ & 29 & 5.0 & 583 \\
\hline $\begin{array}{l}\text { 9. B. H., } 60 \\
\text { Carcinoma kidney }\end{array}$ & 5.8 & 489 & 100 & 3 & 11.6 & 1,093 & 100 & $\begin{array}{l}200- \\
400\end{array}$ & 15 & 8.3 & 622 \\
\hline $\begin{array}{l}\text { 10. J. F., } 49 \\
\text { Glioblastoma }\end{array}$ & 2.5 & 548 & 100 & 4 & 12.4 & 2,516 & 100 & 100 & 5 & 3.9 & 1,479 \\
\hline $\begin{array}{l}\text { 11. M. M., } 41 \\
\text { Carcinoma palate }\end{array}$ & 4.2 & 446 & 100 & 4 & 10.2 & 977 & & & & & \\
\hline $\begin{array}{l}\text { 12. A. E., } 51 \\
\text { Carcinoma uterus }\end{array}$ & 4.7 & 671 & 100 & 2 & 15.2 & 1,122 & & & & & \\
\hline $\begin{array}{l}\text { 13. G. S. } \\
\text { Carcinoma lung }\end{array}$ & 4.7 & 647 & 100 & 3 & 9.9 & 1,350 & & & & & \\
\hline $\begin{array}{l}\text { 3. F. G., } 40 \\
\text { Carcinoma breast }\end{array}$ & 5.2 & 396 & 50 & 15 & 11.3 & 901 & & & & & \\
\hline $\begin{array}{l}\text { 3. F. G., } 40 \\
\text { Carcinoma breast }\end{array}$ & 5.0 & 267 & 25 & 22 & 10.5 & 557 & 25 & $\begin{array}{l}200- \\
400\end{array}$ & 9 & 9.7 & 487 \\
\hline
\end{tabular}

* These values indicate the mean uric acid excretion during the period of thiadiazole administration plus one or two days following cessation of administration, the period during which the thiadiazole effect was evident. Control periods were of similar duration-in most cases, an appropriate number of days immediately preceding thiadiazole administration.

2. In addition to the patients listed in Table I, two patients were given the compound without measurement of the urine uric acid. In these, the elevations of the serum uric acid were similar to those seen in the other subjects. Two additional patients were studied in whom renal complications occurred as a result of marked hyperuricemia :

U.F., a 59 year old woman with metastatic melanocarcinoma, was given $100 \mathrm{mg}$. daily of EA-TDA for four days which resulted in a rise in serum uric acid to 34.8 mg. per cent (control value was $4.5 \mathrm{mg}$. per cent). She developed oliguria with a rise in blood urea nitrogen (BUN) from 6.6 to $46.5 \mathrm{mg}$. per cent. The urine output increased after three days of oliguria with a slow fall to normal in serum uric acid and BUN. There was some evidence of renal functional abnormalities for several weeks. Subsequent administration of $25 \mathrm{mg}$. of EA-TDA daily for two days produced a rise in serum uric acid from 4.6 to $10.3 \mathrm{mg}$. per cent, with a similar rise in urine uric acid. It was concluded that this patient was unusually sensitive to the effects of this compound on uric acid production.

C.S., a 68 year old man with metastatic anaplastic carcinoma of undertermined origin, received $100 \mathrm{mg}$. of EA-TDA daily for five days. His serum uric acid rose to $42.4 \mathrm{mg}$. per cent. Simultaneously, however, he developed nausea and vomiting due to intraperitoneal bleeding. This produced dehydration, oliguria and azotemia. An emergency laparotomy revealed active bleeding from an omental metastasis. He expired five days postoperatively with a markedly elevated serum uric acid and BUN. 
TABLE II

Effect of 2-amino-1,3,4 thiadiazole on uric acid production

\begin{tabular}{|c|c|c|c|c|c|c|}
\hline \multirow[b]{2}{*}{$\begin{array}{l}\text { Patient, } \\
\text { age, } \\
\text { diagnosis }\end{array}$} & \multicolumn{2}{|c|}{ Control period } & \multicolumn{4}{|c|}{ A-TDA period } \\
\hline & $\begin{array}{l}\underset{\text { Serum }}{\text { U.A. }} \\
\text { (max.) }\end{array}$ & $\begin{array}{c}\text { Urine } \\
\text { U.A. } \\
\text { (mean) }\end{array}$ & Dose & $\begin{array}{c}\text { Days of } \\
\text { treat- } \\
\text { ment }\end{array}$ & $\begin{array}{l}\text { Serum } \\
\text { U.A. } \\
\text { (max.) }\end{array}$ & $\begin{array}{l}\text { Urine } \\
\text { U.A. } \\
\text { (mean) }\end{array}$ \\
\hline $\begin{array}{l}\text { 9. B. H., } 60 \\
\text { Carcinoma kidney }\end{array}$ & $\begin{array}{l}m g . \% \\
6.3\end{array}$ & $\begin{array}{l}\text { mg./day } \\
592\end{array}$ & $\begin{array}{l}m g . / d a y \\
50\end{array}$ & 4 & $\begin{array}{l}m g . \% \\
11.6\end{array}$ & $\begin{array}{l}\text { mg./day } \\
929\end{array}$ \\
\hline $\begin{array}{l}\text { 14. L. A., } 70 \\
\text { Carcinoma stomach }\end{array}$ & 4.8 & 171 & 50 & 7 & 10.0 & 803 \\
\hline $\begin{array}{l}\text { 15. S. K., } 84 \\
\text { Carcinoma colon }\end{array}$ & 3.8 & 198 & 50 & 5 & 10.6 & 392 \\
\hline $\begin{array}{l}\text { 7. J. G., } 57 \\
\text { Carcinoma rectum }\end{array}$ & 3.8 & 628 & 50 & 3 & 9.4 & 1,590 \\
\hline
\end{tabular}

II. 2-Amino-1,3,4 thiadiazole $(A-T D A)$ has been used in four patients. (Table II). The results were similar in every respect to those seen with EA-TDA. The dose-response relationship of this compound has not been explored in detail but the effective dosage appears to be similar to that of EA-TDA.4

III. 2,5-Diamino-1,3,4 thiadiazole ( $D A-T D A)$, the compound of this group which has been found inactive against animal tumors (7-9), has been given in gradually increasing doses up to $2 \mathrm{Gm}$. daily, 10 times the highest dose of EA-TDA which has been employed (Table III). At this dose, there was no oral toxicity and no effect on uric acid production in patients who had previously shown the capacity to respond to one of the other compounds (Figure 3). One patient was

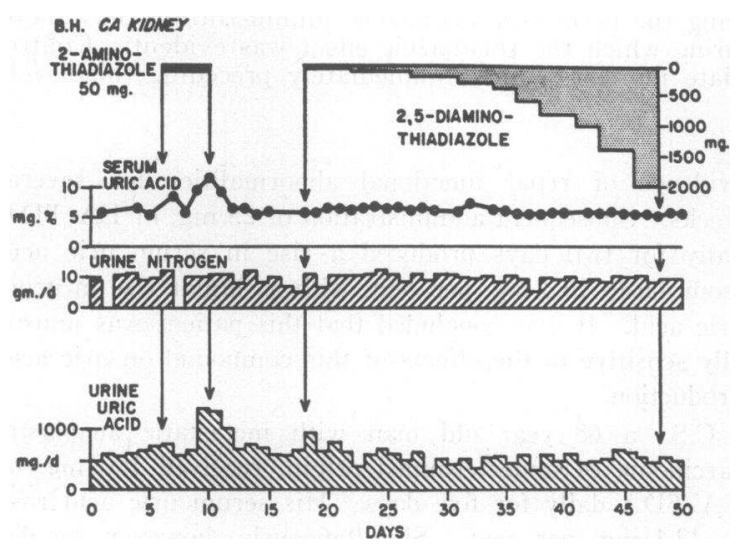

Fig. 3. Course of a Patient Treated with 2-Amino1,3,4 Thiadiazole and 2,5-Diamino-1,3,4 Thiadiazole

4 Since the preparation of this paper 2-acetylamino1,3,4-thiadiazole has also been found to be uricogenic in a dosage similar to that of EA-TDA. given DA-TDA, 1,500 mg. daily, simultaneously with $100 \mathrm{mg}$. daily of EA-TDA. The increase in uric acid production was similar to that which occurred when EA-TDA was given alone. The inactive thiadiazole, therefore, did not prevent the "uricogenic" effect of the active one.

$I V$. Reversal studies: A. Nicotinamide. In view of the observations (7-9) that simultaneous administration of nicotinamide could reverse the anti-tumor effect produced by the 2-substituted thiadiazoles in various animal tumors, nicotinamide has been administered in varying doses to patients receiving the thiadiazoles. In the first such patient to be treated (Table I, Patient No. 3), who was previously reported in detail (6), $200 \mathrm{mg}$. of nicotinamide did not prevent the rise in serum and urine uric acid produced by $200 \mathrm{mg}$. per day of EA-TDA. However, further experiences with this patient using larger doses of nicotinamide and with all patients treated subsequently revealed that nicotinamide in doses equal to or greater than the dosage of EA-TDA could markedly modify or completely block the effect of the thiadiazole. Furthermore, nicotinamide could reverse the hyperuricemia and glossitis while EA-TDA was continued if these signs were allowed to develop before the institution of nicotinamide therapy. Figure 2 illustrates the observations made in a patient who was given varying doses of EA-TDA with and without nicotinamide. The results of the nicotinamide reversal studies are also shown in Table I. Nicotinamide alone has caused no alteration in uric acid production.

$B$. DON. Inasmuch as the thiadiazoles have been found to influence purine synthesis, a group of experiments was undertaken in which com- 
pounds known to inhibit purine synthesis in vitro (17-20) were administered simultaneously with the thiadiazole compounds. In Figure 4 are shown the results of such an experiment in which the glutamine antagonist 6-diazo-5-oxo-L-norleucine (DON) was administered with a dose of EATDA which was later shown to be effective in producing a marked rise in serum and urine uric acid in the same patient. It can be seen that when the administration of DON was started prior to the institution of therapy with EA-TDA, the rise in uric acid was appreciably modified. In a similar experiment in another patient, in which EATDA was administered with a rise, as expected, in serum and urine acid, subsequent administration of DON while continuing EA-TDA resulted in a return to normal of these values. It is of interest that the characteristic glossitis produced by EATDA was not modified by the simultaneous administration of DON. Although DON also can produce glossitis, that which occurred in these cases did not appear to be qualitatively or quantitatively different from that produced by EATDA alone.

In an experiment similar to the one shown in Figure 4, o-diazo-acetyl-L-serine (azaserine), which is also a glutamine analogue, was given in a dose of $9 \mathrm{mg}$. per $\mathrm{Kg}$. daily, simultaneously with $200 \mathrm{mg}$. daily of EA-TDA. It also was effective in nearly completely inhibiting the uricogenic effect of EA-TDA. The appearance of glossitis due to EA-TDA was not prevented.

$V$. Isotope studies. In order to demonstrate further the uricogenic effect of the thiadiazoles and to help clarify the mechanisms of the effect, the incorporation of labeled purine precursors into uric acid was determined. Figure 5 demonstrates a study in which sodium formate- $\mathrm{C}^{14}$ was given

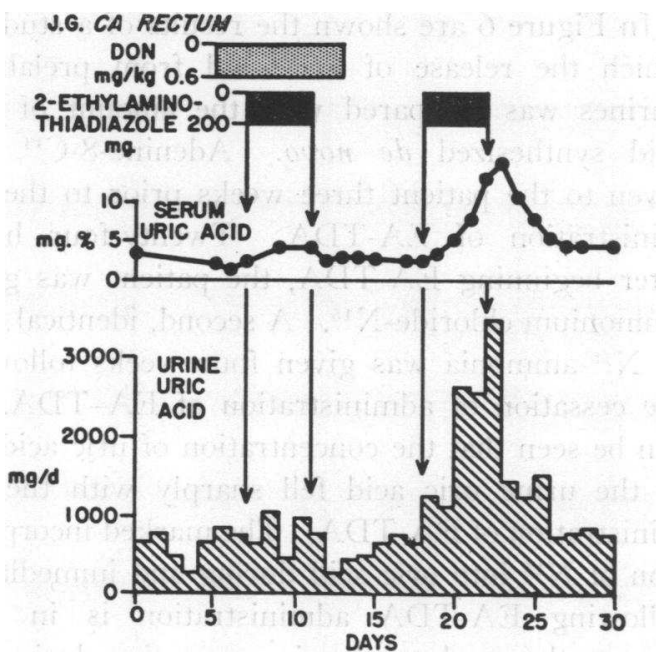

Fig. 4. Course of a Patient Treated with 2-Ethylamino-1,3,4 Thiadiazole and 6-Diazo-5-Oxo-L-NoRLEUCINE (DON)

Note the marked modification of the thiadiazole effect produced by DON.

intravenously to a patient under three different circumstances. The patient, a 68 year old man with far-advanced, metastatic carcinoma of the lung, was given a purine-free diet throughout the period of observation. As shown in Figure 5 the incorporation of $\mathrm{C}^{14}$ into uric acid was markedly increased during treatment with EA-TDA. When EA-TDA and DON were given together the incorporation was similar to that seen during the control period. In a separate study in another patient DON alone was found to produce no effect on the incorporation of sodium formate- $\mathrm{C}^{14}$ into uric acid. In that study a maximum activity of $62 \mathrm{cpm}$ per $\mu \mathrm{M}$ was found in a control period with a maximum of $58 \mathrm{cpm}$ per $\mu \mathrm{M}$ during DON administration.

TABLE III

Effect of 2,5-diamino-1,3,4 thiadiazole on uric acid production

\begin{tabular}{|c|c|c|c|c|c|c|}
\hline \multirow[b]{2}{*}{$\begin{array}{l}\text { Patient, } \\
\text { age, } \\
\text { diagmosis }\end{array}$} & \multicolumn{2}{|c|}{ Control period } & \multicolumn{4}{|c|}{ DA-TDA period } \\
\hline & $\begin{array}{l}\text { Serum } \\
\text { U.A. } \\
\text { (max.) }\end{array}$ & $\begin{array}{c}\text { Urine } \\
\text { U.A. } \\
\text { (mean) }\end{array}$ & Dose & $\begin{array}{c}\text { Days of } \\
\text { treat- } \\
\text { ment }\end{array}$ & $\begin{array}{l}\text { Serum } \\
\text { U.A. } \\
\text { (max.) }\end{array}$ & $\begin{array}{c}\text { Urine } \\
\text { U.A.A. } \\
\text { (mean) }\end{array}$ \\
\hline $\begin{array}{l}\text { 9. B. H., } 60 \\
\text { Carcinoma kidney }\end{array}$ & $\begin{array}{l}\text { mg. \% } \\
6.2\end{array}$ & $\begin{array}{l}m g . / d a y \\
685\end{array}$ & $\begin{array}{l}m g . / d a y \\
50-2,000\end{array}$ & 30 & $\begin{array}{l}m g . \% \\
6.6\end{array}$ & $\begin{array}{c}\text { mg./day } \\
514\end{array}$ \\
\hline $\begin{array}{l}\text { 11. M. M., } 41 \\
\text { Carcinoma palate }\end{array}$ & 5.8 & 333 & $500-1,500$ & 10 & 7.4 & 402 \\
\hline
\end{tabular}


In Figure 6 are shown the results of a study in which the release of uric acid from prelabeled purines was compared with the amount of uric acid synthesized de novo. Adenine-8- $\mathrm{C}^{14}$ was given to the patient three weeks prior to the administration of EA-TDA. Twenty-four hours after beginning EA-TDA, the patient was given ammonium chloride- $\mathrm{N}^{15}$. A second, identical dose of $\mathrm{N}^{15}$-ammonia was given four weeks following the cessation of administration of EA-TDA. It can be seen that the concentration of uric acid- $\mathrm{C}^{14}$ in the urine uric acid fell sharply with the administration of EA-TDA. The marked incorporation of $\mathrm{N}^{15}$ into uric acid during and immediately following EA-TDA administration is in contrast to the much smaller incorporation during the control study four weeks later.

\section{DISCUSSION}

These compounds have been of interest because they have shown the ability to increase markedly the de novo synthesis of uric acid in

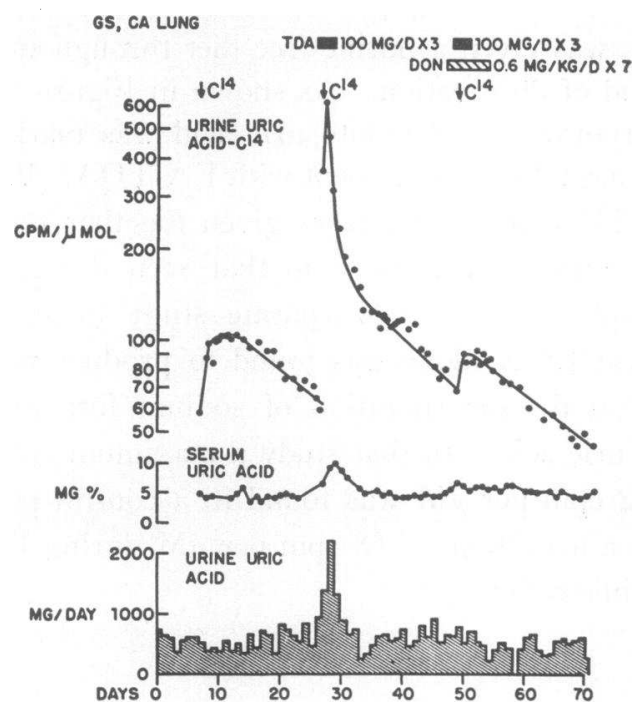

Fig. 5. Study of a Patient Given Sodium Formate$\mathrm{C}^{14}, 200 \mu \mathrm{C}$., on Three Occasions

The second and third phases have been corrected here for the extrapolated values of the prior curves since, in these and other studies, the decay curve has been found to be a straight line in a semilogarithmic plot. Note the marked increase in $\mathrm{C}^{14}$ concentration in urine uric acid as well as the increase in the amount of urine uric acid produced by 2-ethylamino-1,3,4 thiadiazole and the absence of this effect when DON was given with the thiadiazole. man. The parallel increase in uric acid content of both serum and urine have ruled out a renal factor as the cause of the hyperuricemia and there have been no effects on other renal functions except when prolonged or excessive hyperuricemia has resulted in renal shutdown.

Tumor breakdown, which can be achieved by a variety of chemical and physical agents and which can sometimes cause definite increases in serum and urine uric acid (5), has been excluded as the cause of the increased uric acid production occurring with the administration of these compounds; aside from the lack of clinical evidence of tumor regression ${ }^{5}$ nitrogen excretion has not increased in parallel with the uric acid increase. The uricogenic effect of 2-ethylamino thiadiazole in a patient without a neoplastic disease is further evidence that tumor destruction is not contributing to the uric acid pool.

The final evidence that the increase in uric acid production is due to increased de novo synthesis is seen in the isotope studies in which both $\mathrm{N}^{15}$ labeled ammonia and $\mathrm{C}^{14}$-labeled sodium formate were incorporated into uric acid to a much larger extent during thiadiazole administration than during comparable control periods. The sharp drop during EA-TDA administration of the curve of $\mathrm{C}^{14}$-labeled uric acid resulting from the prior administration of adenine- $\mathrm{C}^{14}$ indicates a dilution with unlabeled uric acid. Inasmuch as the ribonucleic acid (RNA), desoxyribose nucleic acid (DNA) and acid-soluble purine pool must be assumed to be uniformly labeled, the influx of unlabeled uric acid is considered to represent uric acid newly synthesized from simple precursors.

Although the precise portion of the metabolic pathway in which the thiadiazole effect occurs has not been determined, further evidence that these compounds augment de novo biosynthesis of uric acid is seen in the fact that their uricogenic effect is blocked by DON and azaserine, compounds whose major site of action has been localized. These glutamine antagonists have been found to block purine biosynthesis at a relatively simple level, the conversion of formylglycineamide ribo-

\footnotetext{
5 The inconsistency between the effect of the thiadiazoles on animal tumors and their lack of effect on human tumors is not unusual. Many substances have been found to inhibit the growth of transplanted animal tumors and to be ineffective in spontaneous cancer in man.
} 
nucleotide (FGAR) to formylglycineamidine ribonucleotide (FGAM). They have also been demonstrated (21) to have a marked effect in inhibiting the biosynthesis of uric acid in the intact chicken by blocking the same step in the metabolic pathway. DON and azaserine, however, have not been found in this laboratory to produce a measurable decrease in normal uric acid production in humans although Benedict and co-workers (22) and Wyngaarden (23) have demonstrated that de novo synthesis is an important source of uric acid in man. The reversal of the thiadiazole-induced exaggeration of purine (uric acid) synthesis by these known inhibitors of purine synthesis may be only quantitatively different from the failure of DON and azaserine to inhibit normal uric acid synthesis in man. On the other hand, there may. be a qualitative difference. The failure of DON and azaserine to prevent the oral toxicity of EA-TDA while inhibiting the uricogenic effect suggests that the action of the thiadiazoles is complex, involving multiple metabolic pathways or involving a single metabolic pathway at multiple levels. It may be postulated that the fundamental mechanism of the thiadiazole effect is in blocking the incorporation of newly synthesized purine molecules into polynucleotides and/or coenzymes with the production of an undefined deficiency state, manifested by glossitis, a sign which is seen in a wide variety of clinical deficiencies. This could stimulate a compensatory exaggeration of purine biosynthesis and the normal oxidation of these purines would result in the observed increase in uric acid production. ${ }^{6}$ DON and azaserine may then block the compensatory mechanism without affecting the related deficiency.

Such a deficiency or metabolic block has not been demonstrated. A clue to its nature, however, may be provided by the ability of niacin or nicotinamide to block the toxicity and the uricogenic effects of the thiadiazoles in man and the anti-tumor effects in animals. The reason for the reversal of TDA effects by nicotinamide is not clear. Although the principal physiological func-

${ }^{6}$ Dr. James Wyngaarden has suggested in a personal communication that the thiadiazoles might act by blocking the synthesis of nicotinamide from tryptophan or its binding by desamido-NMN (nicotinamide mononucleotide)-pyrophosphorylase resulting in greater availability of phosphoribosyl pyrophosphate for purine synthesis.

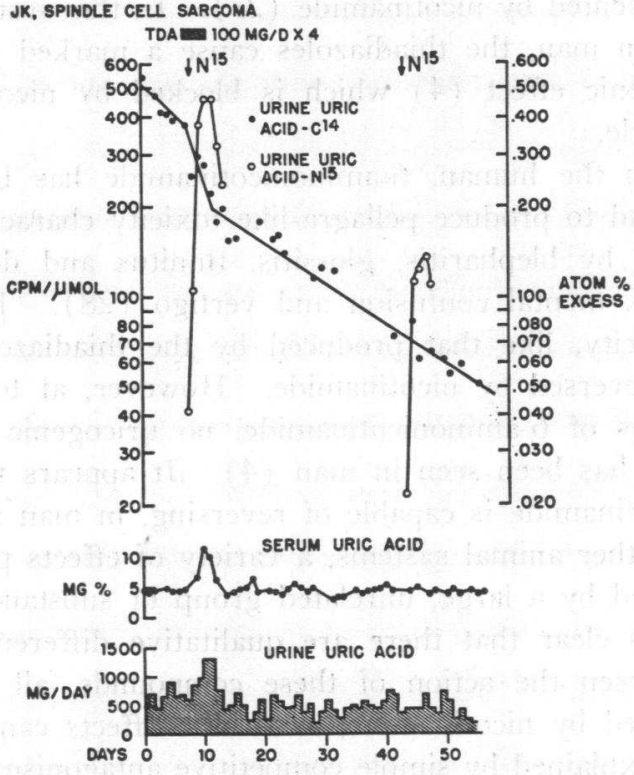

Fig. 6. Study of a Patient who was Given Adenine-8-C ${ }^{14}, 200 \mu \mathrm{C}$., Thre Weeks Prior to 2-EthylAMINo-1,3,4 Thiadiazole

The thiadiazole was given at a time when the decay curve of urine uric acid- $\mathrm{C}^{14}$ was a straight line. Note the sharp drop in $\mathrm{C}^{14}$ concentration in urine uric acid produced by the thiadiazole. Ammonium chloride- $\mathrm{N}^{15}$ was incorporated to a much greater extent when given during thiadiazole administration than during the control study. The second $\mathrm{N}^{15}$ curve has been corrected here for the extrapolated value of the first curve.

tion of nicotinamide is in the synthesis of diphosphopyridine nucleotide (DPN), it should be noted that nicotinamide has been found to oppose the activity of a wide variety of chemicals which do not appear to have a common mechanism of action and which have no apparent relationship to DPN synthesis. The system in which this has been most extensively investigated is the developing chick embryo $(24,25)$, in which a common defect is produced by such unrelated substances as insulin, physostigmine and the nicotinamide analogue, 6-aminonicotinamide, all of which are counteracted by nicotinamide. An identical anatomical lesion is produced by methionine sulfoximine and this cannot be reversed by nicotinamide. Another analogue of nicotinamide, 3-acetylpyridine (26), produces an anatomically different lesion which can also be prevented by nicotinamide. The 2 -substituted thiadiazoles produce no specific teratogenic defect in the chick embryo, but their lethality is 
prevented by nicotinamide (27). In this system, as in man, the thiadiazoles cause a marked uricogenic effect (4) which is blocked by nicotinamide.

In the human, 6-aminonicotinamide has been found to produce pellagra-like toxicity characterized by blepharitis, glossitis, tinnitus and deafness, mental confusion and vertigo (28). This toxicity, like that produced by the thiadiazoles, is reversed by nicotinamide. However, at toxic doses of 6-aminonicotinamide, no uricogenic effect has been seen in man (4). It appears that nicotinamide is capable of reversing, in man and in other animal systems, a variety of effects produced by a large, unrelated group of substances. It is clear that there are qualitative differences between the action of these compounds, all reversed by nicotinamide, and these effects cannot be explained by simple competitive antagonism of nicotinamide. If these substances do function as nicotinamide antagonists, they do so by mechanisms that are not precisely the same and they may actually interfere with different functions of nicotinamide.

Their relationship to nicotinamide has suggested that the thiadiazoles produce an alteration in diphosphopyridine nucleotide (DPN), a coenzyme which contains a purine and a nicotinamide moiety. However, such a relationship has not been established. Quantitative alterations in blood DPN levels in man have not been observed following thiadiazole administration." Ciotti, Kaplan, Goldin and Venditti (29) have demonstrated slight substitution of $\mathrm{C}^{14}$-labeled thiadiazole for the nicotinamide moiety of DPN in vitro but the significance of this observation has not been determined.

There are other compounds currently in clinical use which are structurally related to the thiadiazoles. Among these are acetazoleamide (Diamox $\left.{ }^{(}\right)$which is a 2,5-substituted thiadiazole (Figure 1) and therefore an analogue of 2,5diaminothiadiazole and some of the bacteriostatic sulfonamides. These have not been found, either in this laboratory or in the reported literature, to produce an increase in uric acid production.

${ }^{7}$ Dr. Ralph Barclay has measured blood levels of DPN in two patients treated with 2-ethylamino-thiadiazole and found no differences from control values in the same patients.
A close parallel has been seen between the uricogenic effects of the thiadiazoles in man and their ability to inhibit growth of a variety of animal tumors. In both of these systems the 2-amino- and 2-ethylamino-thiadiazoles have been uniformly active and the 2,5-diamino-thiadiazole and acetazoleamide uniformly inactive. Since the increase in production of uric acid is clearly not a result of lysis of tumor tissue, the tumor-inhibitory effect cannot be considered the direct cause of the uricogenic effect. However, the parallel suggests that the two apparently diverse effects of this group of compounds are associated with the same or similar metabolic phenomena.

Further studies are in progress to attempt to determine the precise mechanism of action of this group of compounds.

\section{SUMMARY}

1. 2-Amino-1,3,4 thiadiazole and 2-ethylamino$1,3,4$ thiadiazole have been found to cause an increase in production of uric acid by a mechanism other than nucleic acid degradation. This appears to be due to an increase in uric acid biosynthesis de novo.

2. The uricogenic effects of these compounds and their oral toxicity can be blocked or reversed by the administration of nicotinamide in equal or greater doses. The glutamine antagonists, 6-diazo5-oxo-L-norleucine and $o$-diazo-acetyl-L-serine, block the uricogenic effects but not the oral toxicity.

3. 2,5-Diamino-1,3,4 thiadiazole, a closely related compound, has no effect on uric acid production.

4. The effect or lack of effect of the thiadiazoles on uric acid production in man is closely correlated with their effect or lack of effect in inhibiting growth of animal tumors.

5. The possibility that the effect of these compounds is due to a block in formation of polynucleotides or coenzymes has been suggested.

\section{ACKNOWLEDGMENT}

The authors wish to thank Drs. David A. Karnofsky and Joseph $\mathrm{H}$. Burchenal for their continuing advice and suggestions in these studies. 


\section{REFERENCES}

1. Benedict, J. D., Forsham, P. H., Roche, M., Soloway, S., and Stetten, DeW., Jr. The effect of salicylates and adrenocorticotropic hormone upon the miscible pool of uric acid in gout. J. clin. Invest. 1950, 29, 1104.

2. Sirota, J., Yu, T. F., and Gutman, A. B. Effect of benemid ( $\mathrm{p}$ [di-n-propylsulfamyl]-benzoic acid) on urate clearance and other discrete renal functions in gouty subjects. J. clin. Invest. 1952 31, 692.

3. Cullen, J. H., Early, L. J., and Fiore, J. M. The occurrence of hyperuricemia during pyrazinamideisoniazid therapy. Amer. Rev. Tuberc. 1956, 74, 289.

4. Krakoff, I. H. Unpublished data.

5. Krakoff, I. H. Urinary uric acid excretion in leukemia in The Leukemias: Etiology, Pathophysiology, and Treatment, J. W. Rebuck, F. H. Bethell and R. W. Monto, Eds. New York, Academic Press Inc., 1957, p. 401.

6. Krakoff, I. H., and Magill, G. B. Effects of 2-ethylamino-1,3,4 thiadiazole $\mathrm{HCl}$ on uric acid production in man. Proc. Soc. exp. Biol. (N. Y.) 1956, $91,470$.

7. Oleson, J. J., Sloboda, A., Troy, W. P., Halliday, S. L., Landes, M. J., Angier, R. B., Semb, J., Cyr, $\mathrm{K}$., and Williams, J. H. The carcinostatic activity of some 2-amino-1,3,4-thiadiazoles. J. Amer. chem. Soc. 1955, 77, 6713 .

8. Burchenal, J. H., and Dagg, M. K. Effects of 6-diazo-5-oxo-L-norleucine and 2-ethylamino-thiadiazole on strains of transplanted mouse leukemia. Proc. Amer. Ass. Cancer Res. 1956, 2, 97.

9. Troy, W. P., Sloboda, A. S., Halliday, S. L., and Oleson, J. J. Derivatives of 2-amino-1,3,4-thiadiazole as niacin antagonists. Fed. Proc. 1956, 15, 372.

10. Forsham, P. H., Thorn, G. W., Pruntz, F. T. G., and Hills, A. G. Clinical studies with pituitary adrenocorticotropin. J. clin. Endocr. 1948, 8, 15.

11. Dubbs, C. A., Davis, F. W., and Adams, W. S. Simple microdetermination of uric acid. J. biol. Chem. 1956, 218, 497.

12. Hawk, P. B., Oser, B. L., and Summerson, W. H. Practical Physiological Chemistry, 13th ed. New York, Blakiston, 1954, pp. 547-8.

13. Loevinger, R., and Berman, M. Efficiency criteria in radioactivity counting. Nucleonics 1951, 9, 26.

14. Rittenberg, D. Preparation of gas samples for mass spectrographic isotope analysis in Preparation and Measurement of Isotopic Tracers, D. W. Wilson, A. O. C. Nier and S. P. Reimann, Eds. Ann Arbor, J. W. Edwards, 1948, p. 31.

15. Ellison, R. R., Karnofsky, D. A., Sternberg, S. S., Murphy, M. L., and Burchenal, J. H. Clinical trials of o-diazoacetyl-L-serine (azaserine) in neoplastic disease. Cancer 1954, 7, 801.
16. Magill, G. B., Myers, W. P. L., Reilly, H. C., Putnam, R. C., Magill, J. W., Sykes, M. P., Escher, G. C., Karnofsky, D. A., and Burchenal, J. H. Pharmacological and initial therapeutic observations on 6-diazo-5-oxo-L-norleucine (DON) in human neoplastic disease. Cancer 1957, 10, 1138.

17. Skipper, H. E., Bennett, L. L., Jr., and Schabel, F. M., Jr. Mechanism of action of azaserine. Fed. Proc. 1954, 13, 298.

18. Hartman, S. C., Levenberg, B., and Buchanan, J. M. Involvement of ATP, 5-phosphoribosylpyrophosphate and L-azaserine in the enzymatic formation of glycinamide ribotide intermediates in inosinic acid biosynthesis. J. Amer. chem. Soc. 1955, 77, 501.

19. Tomisek, A. J., Kelly, H. J., and Skipper, H. E. Chromatographic studies of purine metabolism. I. The effect of azaserine on purine biosynthesis in E. coli using various $\mathrm{C}^{14}$-labeled precursors. Arch. Biochem. 1956, 64, 437.

20. Levenberg, B., Melnick, I., and Buchanan, J. M. Biosynthesis of the purines. XV. The effect of azaL-serine and 6-diazo-5-oxo-L-norleucine on inosinic acid biosynthesis de novo. J. biol. Chem. 1957, 225, 163.

21. Krakoff, I. H., and Karnofsky, D. A. Inhibition of uric acid biosynthesis in birds by $o$-diazoacetyl-Lserine (azaserine) and 6-diazo-5-oxo-L-norleucine (DON). Amer. J. Physiol. 1958, 195, 244.

22. Benedict, J. D., Roche, M., Yu, T. F., Gutman, A. B., and Stetten, D., Jr. Incorporation of glycine nitrogen into uric acid in normal and gouty man. Metabolism 1952, 1, 3.

23. Wyngaarden, J. B. Overproduction of uric acid as the cause of hyperuricemia in primary gout. J. clin. Invest. 1957, 36, 1508.

24. Karnofsky, D. A. The use of the developing chick embryo in pharmacologic research. Stanf. med. Bull. 1955, 13, 247.

25. Landauer, W. On teratogenic effects of pilocarpine in chick development. J. exp. Zool. 1953, 122, 469.

26. Ackermann, W. W., and Taylor, A. Application of a metabolic inhibitor to the developing chick embryo. Proc. Soc. exp. Biol. (N. Y.) 1948, 67, 449.

27. Murphy, M. L., Dagg, C. P., and Karnofsky, D. A. Comparison of teratogenic chemicals in the rat and chick embryos. Pediatrics 1957, 19, 701.

28. Herter, F. P., Frick, H. C., Hyman, G. A., Findlay, C. W., Jr., and Shapiro, D. M. Initial clinical experience with 6-aminonicotinamide. Proc. Amer. Ass. Cancer Res. 1958, 2, 307.

29. Ciotti, M. M., Kaplan, N. O., Goldin, A., and Venditti, J. M. Mechanism of the antileukemic and antinicotinamide action of thiadiazoles. Proc. Amer. Ass. Cancer Res. 1958, 2, 287. 